\title{
Potential Effects of Microplastic on Arbuscular Mycorrhizal Fungi
}

\author{
Eva F. Leifheit ${ }^{1,2 *}$, Anika Lehmann ${ }^{1,2}$ and Matthias C. Rillig ${ }^{1,2}$ \\ ${ }^{1}$ Institut für Biologie, Freie Universität Berlin, Berlin, Germany, ${ }^{2}$ Berlin-Brandenburg Institute of Advanced Biodiversity \\ Research, Berlin, Germany
}

OPEN ACCESS

Edited by:

Jan Jansa,

Academy of Sciences of the Czech Republic (ASCR), Czechia

Reviewed by:

Mohamed Hiji,

Université de Montréal, Canada

Qiang-Sheng Wu,

Yangtze University, China

Sidney Sturmer,

Regional University of Blumenau,

Brazil

${ }^{*}$ Correspondence:

Eva F. Leifheit

e.leifheit@fu-berlin.de

Specialty section:

This article was submitted to Plant Symbiotic Interactions,

a section of the journal

Frontiers in Plant Science

Received: 06 November 2020

Accepted: 05 January 2021

Published: 01 February 2021

Citation:

Leifheit EF, Lehmann A and Rillig MC (2021) Potential Effects of

Microplastic on Arbuscular Mycorrhizal Fungi.

Front. Plant Sci. 12:626709. doi: 10.3389/fpls.2021.626709
Microplastics (MPs) are ubiquitously found in terrestrial ecosystems and are increasingly recognized as a factor of global change (GCF). Current research shows that MP can alter plant growth, soil inherent properties, and the composition and activity of microbial communities. However, knowledge about how microplastic affects arbuscular mycorrhizal fungi (AMF) is scarce. For plants it has been shown that microplastic can both increase and decrease the aboveground biomass and reduce the root diameter, which could indirectly cause a change in AMF abundance and activity. One of the main direct effects of microplastic is the reduction of the soil bulk density, which translates to an altered soil pore structure and water transport. Moreover, especially fibers can have considerable impacts on soil structure, namely the size distribution and stability of soil aggregates. Therefore, microplastic alters a number of soil parameters that determine habitat space and conditions for AMF. We expect that this will influence functions mediated by AMF, such as soil aggregation, water and nutrient transport. We discuss how the impacts of microplastic on AMF could alter how plants deal with other GCFs in the context of sustainable food production. The co-occurrence of several GCFs, e.g., elevated temperature, drought, pesticides, and microplastic could modify the impact of microplastic on AMF. Furthermore, the ubiquitous presence of microplastic also relates to earth system processes, e.g., net primary production (NPP), carbon and nitrogen cycling, which involve AMF as key soil organisms. For future research, we outline which experiments should be prioritized.

Keywords: microplastic, global change, earth system processes, pollution, arbuscular mycorrhizal fungi

\section{INTRODUCTION}

Microplastics (MPs) are ubiquitously found around the globe and are increasingly recognized as a factor of global change (GCF; Rillig and Lehmann, 2020). While MP research has focused on marine and freshwater ecosystems for a long time, recently attention has shifted to terrestrial ecosystems. MP is expected to enter soil ecosystems predominantly in agricultural fields through fertilization with sewage sludge and compost (Nizzetto et al., 2016; van den Berg et al., 2020). But MP emissions also reach soils via atmospheric deposition, runoff or aerial transport from 
nearby roads, where particles and fragments are generated through tire and road wear abrasion or from sports grounds with artificial substrates, through the addition of polymer coated fertilizer, littering, flooding events, or irrigation with wastewater (Piehl et al., 2018; Bergmann et al., 2019; Baensch-Baltruschat et al., 2020; Brahney et al., 2020). However, direct analysis of the concentration of MP in the soil is problematic due to analytical difficulties. MP is quickly incorporated into the soil matrix where it "disappears," and thus cannot be easily distinguished from the soil organic matter without dedicated extraction and analytical protocols.

Arbuscular mycorrhizal fungi (AMF) are a key member of terrestrial ecosystems: by entangling soil aggregates with their hyphae, they improve soil structure and potentially stabilize carbon in soil aggregates (Rillig and Mummey, 2006; Verbruggen et al., 2016). They ramify throughout the soil to access nutrients, which they supply to their symbiotic host partner (Parniske, 2008). In exchange for these nutrients, plants provide carbohydrates and fatty acids to the fungus inside root cells where the fungus forms arbuscules for this exchange (Parniske, 2008; Keymer et al., 2017). Arbuscules or other structures such as hyphae and vesicles inside the roots are intraradical measures for activity and abundance, whereas soil mycelial length, spore numbers, and phosphatase activity are used as extraradical abundance and activity measures, which are complemented by molecular techniques such as qPCR (Thonar et al., 2012). As ubiquitous members of the soil microbial community, AMF face a variety of adverse conditions and likely multiple co-occurring GCFs, including novel pollution agents such as microplastic.

Most plastic types are persistent in the environment and are expected to accumulate in the soil, which likely leads to continuously increasing concentrations of MPs in soils (Rillig, 2012). Current research shows that microplastic can alter plant performance, soil properties, and the composition and activity of microbial communities (e.g., Machado et al., 2018; Boots et al., 2019). Some of the soil biota, e.g., nematodes and Rotifera, can be very sensitive to MP and show alterations of the gut microbiome, reproduction rate, motility and life span, show stress reactions, and malfunctioning metabolism in response to different types of MP (Büks et al., 2020). Effects on AMF can equally be expected, but specific knowledge on MP impacts on AMF is scarce. We expect a number of direct effects of MP on AMF, such as the toxicity of some plastic components (additives), as well as indirect effects of MP on AMF via altered plant performance and soil properties. We elaborate these effects in the following sections, followed by a discussion on potential interactive effects of MP with other GCFs and feedbacks from earth system processes and we finish with an outline of future research priorities.

\section{HYPOTHESIZED DIRECT EFFECTS OF MICROPLASTIC ON AMF}

Microplastic can have direct harmful effects on soil biota as they contain a variety of additives that can be toxic (Kim et al., 2020). The authors of this study demonstrated that the acute toxicity of the MP on nematodes disappeared when the additives were extracted before exposure. Additionally, there is an increasing body of literature showing that organic pollutants (e.g., polycyclic aromatic hydrocarbons or organochlorines such as DDT), polychlorinated biphenyls, antibiotics, herbicides, pesticides, and trace metals can absorb to plastic surfaces (Wang et al., 2019). Especially small MP particles or high concentrations can induce stress reactions, alter metabolic processes, reproduction, and mortality (Büks et al., 2020). MP can directly alter the composition of the bacterial community in soil and for aquatic systems this has been shown for fungal communities (Kettner et al., 2017; Fei et al., 2020). AMF, like other soil biota, can be negatively affected by pollutants, e.g., heavy metals or hydrocarbons (Cabello, 1997; Joner and Leyval, 2003; Wang et al., 2020). We thus expect direct effects of the MP additives or the pollutants absorbed on the MP surface, which will eventually be released upon degradation. Although AMF exhibit a certain tolerance to heavy metals and hydrocarbons, and can even assist in reducing their toxicity to plants, they are negatively affected at high concentrations (Cabello, 1997; Ferrol et al., 2016). Typical reactions of AMF to soil pollutants include reduced root colonization and infectivity, reduced arbuscule and spore numbers or cell damage (Cabello, 1997; Leyval et al., 1997; Desalme et al., 2012; Ferrol et al., 2016). Pharmaceuticals like antibiotics can exhibit mycotoxicity for $\mathrm{AMF}$ as well, reducing hyphal length and spore numbers (Hillis et al., 2008). Additionally, changes in AMF community structure can occur with soil pollution: e.g., in soils with high lead contamination the abundance of Acaulosporaceae and Glomeraceae decreased, while the relative abundance of Paraglomeraceae increased (Faggioli et al., 2019). The binding of (toxic) pollutants to persistent MP would lead to their accumulation in the soil and over time, the pollution load for AMF will be further augmented, considering the projected increases in use of plastic, antibiotics, and other human activities that release pollutants (Tilman et al., 2002; Lebreton and Andrady, 2019; Roberts and Zembower, 2020). At the moment, it is difficult to estimate a realistic time scale for MP degradation and release of components, because there is not enough information on degradation processes in the soil and the diversity of plastic types and sizes is too large.

Microplastics can furthermore directly influence AMF via breakdown products. Especially biodegradable plastics produce dodecanal, which can be accumulated in the rhizosphere and is known to negatively affect plant and fungal growth (Qi et al., 2020). One recent study showed a strong change in AMF community composition and diversity under MP pollution (Wang et al., 2020). The authors found that the relative abundance of AMF taxa depended on type and concentration of MP: e.g., Glomeraceae were reduced in treatments with biodegradable polylactic acid (PLA) compared to the control and treatments with polyethylene (PE); OTU numbers of Ambispora and Archaeosporaceae increased at higher application rates of $\mathrm{MP}$ ( $10 \%$ addition compared to $1 \%$ addition) under PLA and PE for Ambispora and only under PLA for Archaeosporaceae. 
AMF diversity was found to be highest under 10\% PLA addition and, overall, the biodegradable PLA had a larger influence on AMF diversity compared to PE.

\section{HYPOTHESIZED INDIRECT EFFECTS OF MICROPLASTIC ON PLANT HOST, EXTRARADICAL SOIL ENVIRONMENT AND MICROBIAL COMMUNITIES}

The largest influence of MPs on soil is the change in bulk density, which often has positive consequences for plant growth as this reduces the root penetration resistance, improves the water holding capacity (WHC; see Machado et al., 2019) and is often accompanied by a better aeration (Niu et al., 2012). These conditions favor nutrient and water supply to plants, leading to increased root and shoot biomass, but also to altered root traits (Materechera et al., 1992; Machado et al., 2019; Rillig et al., 2019b). This has been demonstrated in recent studies, where MP reduced the root diameter or increased the fine root length (Machado et al., 2019; Lehmann et al., 2020a). However, from a mere change in diameter or length of fine roots, conclusions on AMF reactions cannot be drawn as there are important functional differences within fine roots: First to third order fine roots are the absorptive part of the root system, where most of the AMF structures are usually found, whereas higher order fine roots are more active in transport and less likely to host AMF (McCormack et al., 2015). Additionally, thin diameter fine roots have a higher absorptive surface area compared to thicker fine roots and can show lower colonization rates by AMF because they do not need to rely on a mycorrhizal partner for nutrient uptake (Eissenstat et al., 2015). Fine root traits differ substantially between plant types, e.g., the average of absorptive fine roots is $33 \%$ for woody plants and $81 \%$ for herbaceous plants (McCormack et al., 2015). Although general predictions of the effect of altered root traits on AMF colonization is difficult with the current literature, it is fair to assume that altered root traits will likely lead to changes in intraradical and extraradical fungal traits, such as root colonization, hyphal extension, abundance, and branching behavior (Rillig et al., 2015; Cockerton et al., 2020). Two studies have found an increase in root colonization by 8 and $22 \%$, respectively, with polyester fiber addition, supporting this postulation (Machado et al., 2019; Lehmann et al., 2020a). However, other plastic types (PA, PEHD, PET, PP, and PS) have not induced an increase in colonization (Machado et al., 2019). Therefore, the effect predominantly depends on the MP parameters (concentration, type, shape, and additives), but also on the specific host-symbiont-relationship: A mycorrhizal symbiosis with a highly dependent plant host might be more strongly influenced by MP-induced alterations compared to a symbiosis in which the plant host is not as dependent on AMF; mycorrhizal dependent plants might profit more from increased AMF activity, i.e., receive more nutrients or water, supporting plant growth. Additionally, there will certainly be differences in the reactions to MP between single AMF species, i.e., some species might be more susceptible to adverse soil conditions (see section "Hypothesized direct effects of microplastic on AMF").

In some cases, MP has reduced plant growth (Qi et al., 2018; Wang et al., 2020), which could limit the $C$ allocation to AMF, and thus reduce AMF abundance and activity, including the supply of nutrients and water to the plant.

Microplastic additions to soil clearly influence soil structure: Laboratory studies found positive and negative effects, but reductions of aggregate stability and aggregate size have been observed more frequently (Lehmann et al., 2020b). Especially fibers with their linear shape can reduce soil aggregate stability and mean weight diameter (by currently unknown mechanisms; Lehmann et al., 2020b), and thus pore size distribution. Smaller pores and improved oxygen availability could change hyphal ramification (Crawford, 1992; Drew et al., 2003). In relation with a reduced bulk density of the soil through MP addition it can be expected that hyphae, like roots, experience a reduced penetration resistance and will thus be able to explore more soil space. This assumption is supported by several studies that show increased root growth due to decreased soil bulk density, leading to improved root colonization with AMF, which facilitated nutrient uptake by the plants (Nadian et al., 1996; Entry et al., 2002). Assuming a reduced bulk density and smaller mean weight diameter of soil aggregates, associated with smaller soil pores, changes in water transport and WHC are expected. Soil water is usually only available to plants in soil pores $>5 \mu \mathrm{m}$ (Weil and Brady, 2017). These smaller soil pores can easily be penetrated by AM hyphae, which can have diameters as small as $1.2 \mu \mathrm{m}$ (Dodd et al., 2012). The creation of more smaller pores by MP could thus foster the AMF assisted water supply to plants.

Another soil property that can be changed by MP is the soil $\mathrm{pH}$. Depending on polymer type and chemistry, $\mathrm{pH}$ can be increased or decreased: in a recent study non-biodegradable PE decreased the soil $\mathrm{pH}$, while biodegradable PLA increased the soil $\mathrm{pH}$ and such effects on soil $\mathrm{pH}$ can affect AMF community composition (Wang et al., 2020); however, in another study, high density polyethylene decreased the soil $\mathrm{pH}$ but PLA had no effect (Boots et al., 2019). Soil pH plays a crucial role for the composition of microbial communities in general and of AMF communities in particular (Porter et al., 1987; Aciego Pietri and Brookes, 2009). Thus, Wang et al. (2020) suggest that the observed effects of MP on the AMF community are mediated by soil $\mathrm{pH}$.

Microplastic additions to soil have varying effects on the overall microbial community composition and activity, likely as a function of concentration and chemical composition of MP (Liu et al., 2017; Machado et al., 2018, 2019; Yu et al., 2020). The underlying mechanisms can be assumed to be in the change of soil properties, especially bulk density, which improves the aeration of the soil and could thus stimulate aerobic microorganisms; or more generally speaking MP induces a shift in the microbial community composition (Liu et al., 2017). Ren et al. (2020) studied effects of two different MP particle sizes $(<150$ and $<13 \mu \mathrm{m})$ on microbial communities and found increases and decreases of richness and diversity, depending on MP particle size, with smaller particles tending 
to increase these parameters. When MP was added to the soil, the microbial community structure changed, e.g., Actinobacteria increased in soils with MP, whereas other groups such as Proteobacteria or Acidobacteria, and for smaller particles also some fungal groups, e.g., Basidiomycota and Chytridiomycota were reduced in MP treatments (Ren et al., 2020). Similar observations, i.e., dominating Actinobacteria and reduced Proteobacteria, have been made by other authors (Huang et al., 2019; Zhang et al., 2019). The soil microbial community composition can have a strong influence on AMF: for example, there are "mycorrhiza helper bacteria" (e.g., Pseudomonas sp., Burkholderia sp.) that facilitate root colonization or hyphal growth from spores (Frey-Klett et al., 2007; Viollet et al., 2017) and nitrogen-fixing bacteria can help AMF to maximize nutrient acquisition in the host (van der Heijden et al., 2016). Proteobacteria, which can be reduced with MP pollution (Ren et al., 2020), can have interactions with AMF: their presence can alter the structure of AMF assemblages and in contaminated soils it can increase root colonization (Dagher et al., 2020).

In addition to microbial community composition the microbial activity can be altered by MP (Liang et al., 2019). One of the mechanisms that can be responsible for this alteration is the addition of an energy resource through MP, as MP itself represents organic carbon (Rillig, 2018). Although generally inert, MPs are mainly composed of carbon, which can partly leach as dissolved organic carbon before fragmentation occurs (Romera-Castillo et al., 2018). The degradation of thermoplastics in soil varies among plastic types and largely depends on the presence of UV-light (Scalenghe, 2018; Chamas et al., 2020). Elastomers such as tire particles can have a rather short half-life of only 16 months (Baensch-Baltruschat et al., 2020). This introduces an artificial resource into the soil that potentially changes the activity of the natural microbial community. This effect has been observed in several studies: e.g., Machado et al. (2019) found an increase in fluorescein diacetate hydrolase (FDA) by several MP types (polyamid beads, polyester fibers, and pellets of high density polyethylene); Liu et al. (2017) found an increase in FDA and phenol oxidase by polypropylenemicroparticles. In a plastic-free soil, it could be shown that there are strong synergistic interactions between Rhizophagus irregularis and other soil microbes: more than half of the $\mathrm{N}$ that the AMF provided to the plant could be related to a synergistic interaction with the host and the soil microbial community (Hestrin et al., 2019). The MP-induced increase in microbial activity could have an indirect effect on AMF: it could trigger similar synergies between AMF and other soil microbes, leading to increased nutrient uptake by plants.

On the other hand, there are studies showing negative effects of MP on enzyme activities, e.g., polyethylene mulching film reduced catalase, laccase, and phenol oxidase (Yu et al., 2020). Differences among studies can be explained by use of different MP types, concentrations, and experiment durations. Some MP types might have toxic effects (additives, absorbed pollutants, see section "Hypothesized direct effects of microplastic on AMF") or alter the soil properties in a way which is disadvantageous for some species, thus reducing overall activity and enzyme production (Yu et al., 2020). These MP-induced reduced microbial activities could also have an indirect effect on AMF: it could prevent synergistic interactions between AMF and other microbes or reduce positive interactions between $\mathrm{AMF}$ and "mycorrhiza helper bacteria" if their activity is decreased as a consequence to MP pollution.

\section{EFFECTS OF MICROPLASTIC ON AMF IN A PERSPECTIVE OF GLOBAL CHANGE}

Long-term consequences of MP effects cannot currently be foreseen, as effects are only studied in the short-term and there are no realistic estimates of MP accumulation in soils. But long-term predictions are necessary as deposited MP will interact with other environmental impacts in the future. In fact, MP is increasingly recognized as a GCF (Rillig and Lehmann, 2020) and should thus be studied in the context of other GCFs, instead of being regarded in isolation.

As MP is now found in almost every ecosystem around the globe, multiple GCFs will likely occur in combination. The co-occurrence of several GCFs could intensify the impact of each single factor (Rillig et al., 2019d). For grassland ecosystems, in which the AM symbiosis is the dominant mycorrhizal type, the occurrence of GCFs such as elevated temperature, elevated $\mathrm{CO}_{2}$, drought, pesticides, heavy metals, and MP is likely. MP research in general has been heavily focused on agricultural systems; this means, we know little about effects in other ecosystem types (such as tropical forests or Mediterranean woodlands), and the same applies to effects on AMF. Elevated $\mathrm{CO}_{2}$ has been shown to stimulate AMF activity (Sanders et al., 1998; Drigo et al., 2010), like MP did for AMF colonization (Machado et al., 2019; Lehmann et al., 2020a). AMF have repeatedly been proposed as an important contributor for sustainable agriculture, where they contribute to resistance and resilience against GCFs such as drought, salinity, but also against pathogens (Veresoglou and Rillig, 2012; Rillig et al., 2016, 2019a; Begum et al., 2019). This role, however, can be challenged if AMF are affected by MP. If MP alters soil porosity and water transport of the soil, AMF-mediated supply with water and nutrients to plants could be assigned a different relevance in both directions. In a recent study, it could not be shown that AMF helped mitigate negative effects of the GCFs MP and drought (Lehmann et al., 2020a), which would represent a diminished role for AMF in ecosystem resilience. It is possible that a negative impact of MP prevented the plant protection that AMF usually provide. If AMF are directly affected by MP, e.g., its toxic components, their ability to protect plants from pathogens or co-occurring GCFs could be changed. We think that this is an important question highlighting the role of AMF for sustainable agriculture in times of global change and for the production of healthy, nutritional food.

Agricultural soils are among the most strongly MP-polluted terrestrial ecosystems because they receive organic fertilizers (e.g., compost, sewage sludge, and biowaste fermentation 
digestates) that can contain high numbers of MP particles (Mahon et al., 2017; Weithmann et al., 2018) and additional sources of MP such as fragments from mulching films that can be extensive (Zhang et al., 2019). Many crops form AM-symbioses. The association of a crop-host with AMF can have positive effects on nutrient uptake and biomass yield, can enhance drought-, metal-, and salinity-tolerance, reduce nutrient leaching, improve soil structure, and increase plant biodiversity (Thirkell et al., 2017). AMF have been proposed to assist in stabilizing sustainable forest and agricultural productivity in the struggle with increasing impact of GCFs (Solaiman et al., 2014; Sosa-Hernández et al., 2019), which now include MPs. However, the colonization by AMF can also reduce yields, depending on the crop species identity and soil nutrient status (Hoeksema et al., 2010). Many of the well-recognized AMF functions (especially improvement of soil structure and $\mathrm{N}$ retention) are connected to key ecosystem services that are important for soil health and eventually for human health, as humans depend on the production of healthy food from soils and the filtration of water for potable groundwater (Lehmann et al., 2020c). MP has the potential to interfere with these important ecosystem functions, as outlined in the sections above, consequently affecting nutrient cycling, i.e., nutrient supply and release of $\mathrm{N}$, with spillover effects on net primary production (NPP). AMF often increase the nutrient status of crops, thereby improving food quality (Thirkell et al., 2017). MP often increases plant growth, but if this positive effect is supported by increased nutrient uptake through an association with AMF is currently not known.

The current state-of-the-art only shows us pieces of a larger puzzle, in which we know that AMF, MP, and other GCFs all contribute to soil and plant biodiversity (Lozano and Rillig, 2020), which are also key for soil (and human) health. But how these factors interact and what the outcome of their interactions are, is difficult to predict (Rillig et al., 2019d).

\section{POTENTIAL EARTH SYSTEM FEEDBACKS AND THE ROLE OF AMF}

Accumulation of MP in the soil has the potential to interfere with earth system processes such as NPP (Rillig and Lehmann, 2020). Enhanced NPP, i.e., enhanced plant growth, will lead to a change in root exudation quantity and quality. Increased $\mathrm{C}$ allocation to roots will likely also alter $\mathrm{C}$ allocation to AMF and subsequently process rates of $\mathrm{P}$ and $\mathrm{N}$ cycling, for which AMF play a major role (van der Heijden et al., 2008). Furthermore, AMF play a role in carbon cycling in the soil (Cheng et al., 2012; Averill et al., 2014; Leifheit et al., 2015). It has been postulated that during the decomposition of labile litter AMF stimulate other microbes that increase decomposition (Cheng et al., 2012) and thus soil respiration, with more C loss as $\mathrm{CO}_{2}$. MP-induced changes in AMF activity would thus create a feedback loop to the atmosphere, where increased levels of $\mathrm{CO}_{2}$ foster NPP that is again influenced by MP, while at the same time plant productivity is the main resource for AMF determining their activity.
Another earth system feedback loop might occur with nitrogen. Nutrient cycles around the globe are changing, mainly the $\mathrm{N}$ cycle due to ubiquitous $\mathrm{N}$ deposition. $\mathrm{N}$ inputs introduce nutrient imbalances in the soil leading to altered microbial activity. MP induced increase in microbial activity (and mobilization of $\mathrm{N}$ ) and $\mathrm{N}$ inputs could lead to more $\mathrm{N}_{2} \mathrm{O}$ emissions from soil. Increased $\mathrm{N}$ release in the soil plus atmospheric $\mathrm{N}$ deposition could reduce AMF performance, possibly affecting AMF's potential to reduce $\mathrm{N}$ emissions from soil (Asghari and Cavagnaro, 2012; Storer et al., 2018; Sosa-Hernández et al., 2019), thus fostering greenhouse gas emissions from the soil to the atmosphere. MP thus has the potential to alter the nitrogen cycle and the role of AMF in the cycle, finally leading to increased turnover rates and reduced AMF activity.

\section{FUTURE RESEARCH PRIORITIES}

At the moment, we cannot fully assess the relevance of MP for AMF. We here propose research areas at individual scales, the corresponding research topics for microplastic effects on $\mathrm{AMF}$ and give a conceptual summary of these ideas in Figure $\mathbf{1 .}$

As AMF are obligate symbionts, it will be difficult to disentangle direct impacts of MP on AMF and indirect effects via plants, soil properties, or the microbial community. Therefore, basic ecotoxicological research is needed for AMF, how MP affects the AMF community composition, the diversity and their functioning. For these studies, MP with known or without additives is needed, to differentiate between effects from chemistry and plastic traits such as shape or size. In order to draw generalizations for MP effects on this key symbiont, studies should then use different MP (with known chemistry) and soil types. Such experiments with a focus on the fungal part of the symbiosis would need to use compartmentalized designs, in which the fungal extraradical mycelium in the soil is physically separated from the root system, using mesh impenetrable to roots. The addition of MP would then be in these fungal compartments to prioritize effects on the mycobionts. More controlled studies could also be carried out using soil-free in vitro culture systems; here, also the fungal mycelium could be separated from the root.

Once this baseline is established, the focus should move to the study of interactions of MP with other GCFs and their effects on AMF. For this question, factorial experiments with other key factors are needed, or new types of designs that can simultaneously take into account a larger number of factors (e.g., Rillig et al., 2019d) should be pursued. Such experiments should focus on the entire plant-AM symbiotic system and its responses.

Research on MP in soils has emerged only a few years ago and is still based on a number of assumptions, because of the lack of systematic MP quantification in soils, in part due to the absence of suitable high-throughput analytical methods. Hence, our knowledge about MP concentrations in the environment is limited. Additionally, concentrations will differ by orders of magnitude according to the distance from a point source of emission. Current laboratory research thus uses 


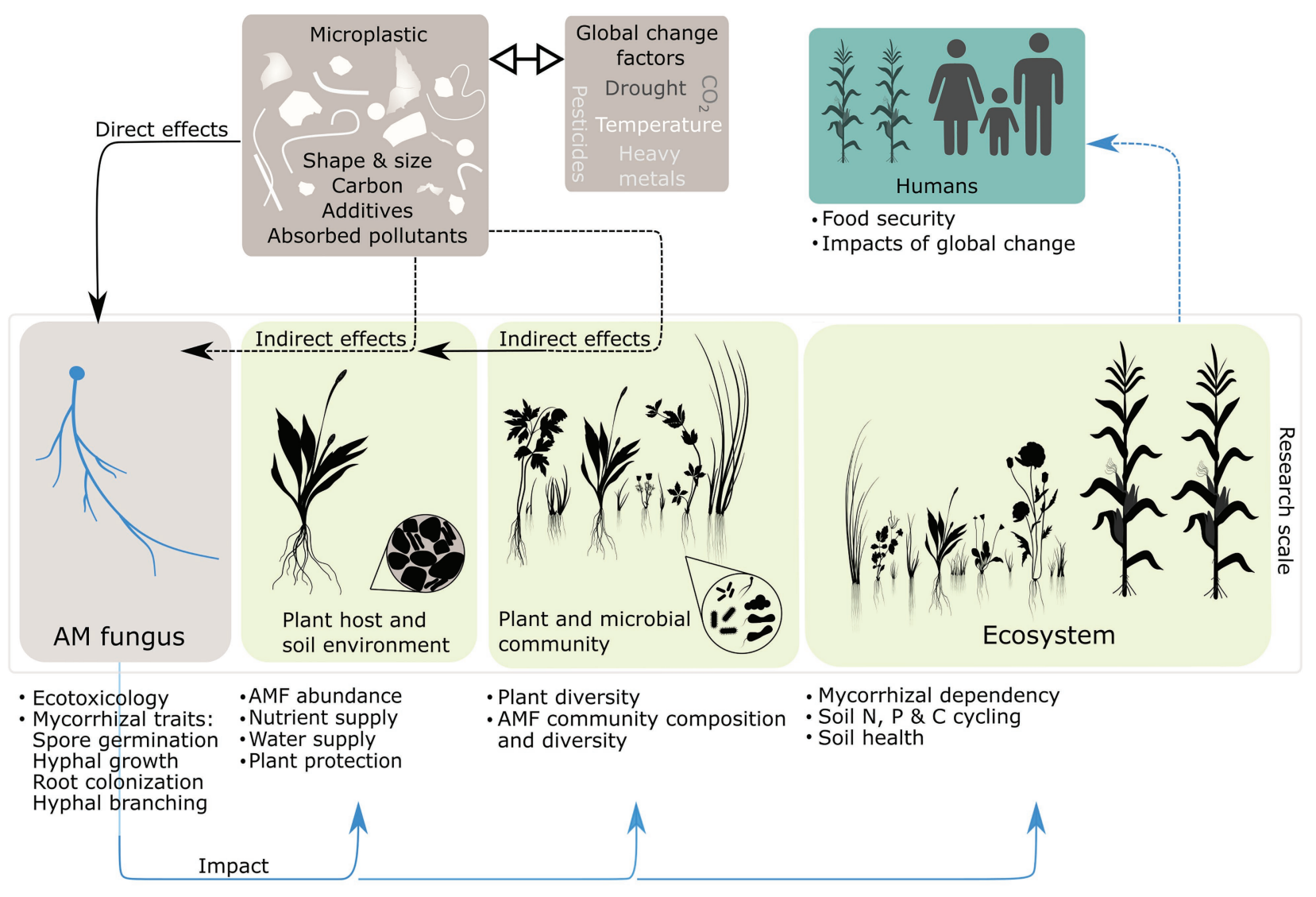

FIGURE 1 | Proposed research scales for microplastic (MP) effects on arbuscular mycorrhizal fungi (AMF) and the corresponding research topics for AMF (text fields). Dashed lines represent indirect effects and solid lines represent direct effects. Black arrows represent the potential impact of microplastic and blue arrows represent the potential impact of microplastic-induced changes in the arbuscular mycorrhiza (AM) symbiosis. The $\leftrightarrow$ symbol indicates potential interactions of microplastic with other factors of global change (GCFs).

concentrations that might not be representative of the situation in the field. Moreover, effects of MP depend on polymer type, its additives and shape (Rillig et al., 2019c), and current analytical methods do not capture this level of detail. Due to these issues (uncertain concentration and chemistry), it is difficult to perform observational studies in the field with native AMF communities under realistic conditions.

Finally, research also needs to move to the plant community level, to more fully explore how AMF and a host community respond to MP. This type of experiment also opens the door to an ecosystem-level assessment (Rillig and Lehmann, 2020), and could include treatments in which mycorrhizal fungi have either been added or not; this way, we will learn how a plant communitylevel or ecosystem-level response to MP will depend on mycorrhiza.

\section{DATA AVAILABILITY STATEMENT}

The original contributions presented in the study are included in the article/supplementary material, further inquiries can be directed to the corresponding author.

\section{AUTHOR CONTRIBUTIONS}

EL wrote the first draft of the paper. EL and AL created the artwork. All authors contributed to the article and approved the submitted version.

\section{FUNDING}

EL acknowledges funding from Deutsche Forschungsgemeinschaft (LE 3859/1-1). MR acknowledges funding from an ERC Advanced Grant (694368) and from the Federal Ministry of Education and Research (BMBF) for the projects BIBS and $\mu$ Plastic.

\section{ACKNOWLEDGMENTS}

We acknowledge support by the Open Access Publication Initiative of Freie Universität Berlin. 


\section{REFERENCES}

Asghari, H. R., and Cavagnaro, T. R. (2012). Arbuscular mycorrhizas reduce nitrogen loss via leaching. PLoS One 7:e29825. doi: 10.1371/journal. pone. 0029825

Averill, C., Turner, B. L., and Finzi, A. C. (2014). Mycorrhiza-mediated competition between plants and decomposers drives soil carbon storage. Nature 505, 543-545. doi: 10.1038/nature12901

Baensch-Baltruschat, B., Kocher, B., Stock, F., and Reifferscheid, G. (2020). Tyre and road wear particles (TRWP)-A review of generation, properties, emissions, human health risk, ecotoxicity, and fate in the environment. Sci. Total Environ. 733:137823. doi: 10.1016/j.scitotenv.2020.137823

Begum, N., Qin, C., Ahanger, M. A., Raza, S., Khan, M. I., Ashraf, M., et al. (2019). Role of arbuscular mycorrhizal fungi in plant growth regulation: implications in abiotic stress tolerance. Front. Plant Sci. 10:1068. doi: 10.3389/ fpls.2019.01068

Bergmann, M., Mützel, S., Primpke, S., Tekman, M. B., Trachsel, J., and Gerdts, G. (2019). White and wonderful? Microplastics prevail in snow from the Alps to the Arctic. Sci. Adv. 5:eaax1157. doi: 10.1126/sciadv.aax1157

Boots, B., Russell, C. W., and Green, D. S. (2019). Effects of microplastics in soil ecosystems: above and below ground. Environ. Sci. Technol. 53, 11496-11506. doi: 10.1021/acs.est.9b03304

Brahney, J., Hallerud, M., Heim, E., Hahnenberger, M., and Sukumaran, S. (2020). Plastic rain in protected areas of the United States. Science 368, 1257-1260. doi: 10.1126/science.aaz5819

Büks, F., Schaik, N. L. V., and Kaupenjohann, M. (2020). What do we know about how the terrestrial multicellular soil fauna reacts to microplastic? SOIL 6, 245-267. doi: 10.5194/soil-6-245-2020

Cabello, M. N. (1997). Hydrocarbon pollution: its effect on native arbuscular mycorrhizal fungi (AMF). FEMS Microbiol. Ecol. 22, 233-236. doi: 10.1111/ j.1574-6941.1997.tb00375.x

Chamas, A., Moon, H., Zheng, J., Qiu, Y., Tabassum, T., Jang, J. H., et al. (2020). Degradation rates of plastics in the environment. ACS Sustain. Chem. Eng. 8, 3494-3511. doi: 10.1021/acssuschemeng.9b06635

Cheng, L., Booker, F. L., Tu, C., Burkey, K. O., Zhou, L. S., Shew, H. D., et al. (2012). Arbuscular mycorrhizal fungi increase organic carbon decomposition under elevated CO2. Science 337, 1084-1087. doi: 10.1126/science.1224304

Cockerton, H. M., Li, B., Stavridou, E., Johnson, A., Karlström, A., Armitage, A. D., et al. (2020). Genetic and phenotypic associations between root architecture, arbuscular mycorrhizal fungi colonisation and low phosphate tolerance in strawberry (Fragaria $\times$ ananassa). BMC Plant Biol. 20:154. doi: 10.1186/ s12870-020-02347-x

Crawford, R. M. M. (1992). "Oxygen availability as an ecological limit to plant distribution" in Advances in ecological research. eds. M. Begon and A. H. Fitter (London and San Diego, CA: Academic Press), 93-185.

Dagher, D. J., de la Providencia, I. E., Pitre, F. E., St-Arnaud, M., and Hijri, M. (2020). Arbuscular mycorrhizal fungal assemblages significantly shifted upon bacterial inoculation in non-contaminated and petroleum-contaminated environments. Microorganisms 8:602. doi: 10.3390/microorganisms8040602

Desalme, D., Chiapusio, G., Bernard, N., Gilbert, D., Toussaint, M. L., and Binet, P. (2012). Arbuscular mycorrhizal fungal infectivity in two soils as affected by atmospheric phenanthrene pollution. Water Air Soil Pollut. 223, 3295-3305. doi: 10.1007/s11270-012-1110-z

Dodd, J., Boddington, C., Rodriguez, A., Chavez, M. D. C. A. G., and Mansur, I. (2012). Mycelium of arbuscular mycorrhizal fungi (AMF) from different genera: form, function and detection. Plant Soil 226, 131-151. doi: 10.1023/A:1026574828169

Drew, E. A., Murray, R. S., Smith, S. E., and Jakobsen, I. (2003). Beyond the rhizosphere: growth and function of arbuscular mycorrhizal external hyphae in sands of varying pore sizes. Plant Soil 251, 105-114. doi: 10.1023/ A:1022932414788

Drigo, B., Pijl, A. S., Duyts, H., Kielak, A. M., Gamper, H. A., Houtekamer, M. J., et al. (2010). Shifting carbon flow from roots into associated microbial communities in response to elevated atmospheric $\mathrm{CO}_{2}$. Proc. Natl. Acad. Sci. U. S. A. 107, 10938-10942. doi: 10.1073/pnas.0912421107

Eissenstat, D. M., Kucharski, J. M., Zadworny, M., Adams, T. S., and Koide, R. T. (2015). Linking root traits to nutrient foraging in arbuscular mycorrhizal trees in a temperate forest. New Phytol. 208, 114-124. doi: 10.1111/nph.13451
Entry, J. A., Rygiewicz, P. T., Watrud, L. S., and Donnelly, P. K. (2002). Influence of adverse soil conditions on the formation and function of arbuscular mycorrhizas. Adv. Environ. Res. 7, 123-138. doi: 10.1016/S1093-0191(01)00109-5

Faggioli, V., Menoyo, E., Geml, J., Kemppainen, M., Pardo, A., Salazar, M. J., et al. (2019). Soil lead pollution modifies the structure of arbuscular mycorrhizal fungal communities. Mycorrhiza 29, 363-373. doi: 10.1007/s00572-019-00895-1

Fei, Y., Huang, S., Zhang, H., Tong, Y., Wen, D., Xia, X., et al. (2020). Response of soil enzyme activities and bacterial communities to the accumulation of microplastics in an acid cropped soil. Sci. Total Environ. 707:135634. doi: 10.1016/j.scitotenv.2019.135634

Ferrol, N., Tamayo, E., and Vargas, P. (2016). The heavy metal paradox in arbuscular mycorrhizas: from mechanisms to biotechnological applications. J. Exp. Bot. 67, 6253-6265. doi: 10.1093/jxb/erw403

Frey-Klett, P., Garbaye, J., and Tarkka, M. (2007). The mycorrhiza helper bacteria revisited. New Phytol. 176, 22-36. doi: 10.1111/j.1469-8137.2007.02191.x

Hestrin, R., Hammer, E. C., Mueller, C. W., and Lehmann, J. (2019). Synergies between mycorrhizal fungi and soil microbial communities increase plant nitrogen acquisition. Commun. Biol. 2:233. doi: 10.1038/s42003-019-0481-8

Hillis, D. G., Antunes, P., Sibley, P. K., Klironomos, J. N., and Solomon, K. R. (2008). Structural responses of Daucus carota root-organ cultures and the arbuscular mycorrhizal fungus, glomus intraradices, to 12 pharmaceuticals. Chemosphere 73, 344-352. doi: 10.1016/j.chemosphere.2008.05.063

Hoeksema, J. D., Chaudhary, V. B., Gehring, C. A., Johnson, N. C., Karst, J., Koide, R. T., et al. (2010). A meta-analysis of context-dependency in plant response to inoculation with mycorrhizal fungi. Ecol. Lett. 13, 394-407. doi: 10.1111/j.1461-0248.2009.01430.x

Huang, Y., Zhao, Y., Wang, J., Zhang, M., Jia, W., and Qin, X. (2019). LDPE microplastic films alter microbial community composition and enzymatic activities in soil. Environ. Pollut. 254:112983. doi: 10.1016/j.envpol.2019.112983

Joner, E. J., and Leyval, C. (2003). Rhizosphere gradients of polycyclic aromatic hydrocarbon (PAH) dissipation in two industrial soils and the impact of arbuscular mycorrhiza. Environ. Sci. Technol. 37, 2371-2375. doi: 10.1021/ es020196y

Kettner, M. T., Rojas-Jimenez, K., Oberbeckmann, S., Labrenz, M., and Grossart, H. -P. (2017). Microplastics alter composition of fungal communities in aquatic ecosystems. Environ. Microbiol. 19, 4447-4459. doi: 10.1111/1462-2920.13891

Keymer, A., Pimprikar, P., Wewer, V., Huber, C., Brands, M., Bucerius, S. L., et al. (2017). Lipid transfer from plants to arbuscular mycorrhiza fungi. Elife 6:e29107. doi: 10.7554/eLife.29107

Kim, S. W., Waldman, W. R., Kim, T. -Y., and Rillig, M. C. (2020). Effects of different microplastics on nematodes in the soil environment: tracking the extractable additives using an ecotoxicological approach. Environ. Sci. Technol. 54, 13868-13878. doi: 10.1021/acs.est.0c04641

Lebreton, L., and Andrady, A. (2019). Future scenarios of global plastic waste generation and disposal. Palgrave Commun. 5:11. doi: 10.1057/ s41599-018-0212-7

Lehmann, J., Bossio, D. A., Kögel-Knabner, I., and Rillig, M. C. (2020c). The concept and future prospects of soil health. Nat. Rev. Earth Environ. 1, 544-553. doi: 10.1038/s43017-020-0080-8

Lehmann, A., Leifheit, E. F., Feng, L., Bergmann, J., Wulf, A., and Rillig, M. C. (2020a). Microplastic fiber and drought effects on plants and soil are only slightly modified by arbuscular mycorrhizal fungi. Soil Ecol. Lett. doi: 10.1007/ s42832-020-0060-4

Lehmann, A., Leifheit, E. F., Gerdawischke, M., and Rillig, M. C. (2020b). Microplastics have shape- and polymer-dependent effects on soil processes. bioRxiv [Preprint]. doi: 10.1101/2020.06.02.130054

Leifheit, E. F., Verbruggen, E., and Rillig, M. C. (2015). Arbuscular mycorrhizal fungi reduce decomposition of woody plant litter while increasing soil aggregation. Soil Biol. Biochem. 81, 323-328. doi: 10.1016/j. soilbio.2014.12.003

Leyval, C., Turnau, K., and Haselwandter, K. (1997). Effect of heavy metal pollution on mycorrhizal colonization and function: physiological, ecological and applied aspects. Mycorrhiza 7, 139-153. doi: 10.1007/ s005720050174

Liang, Y., Lehmann, A., Ballhausen, M. -B., Muller, L., and Rillig, M. C. (2019). Increasing temperature and microplastic fibers jointly influence soil aggregation by saprobic fungi. Front. Microbiol. 10:2018. doi: 10.3389/ fmicb.2019.02018 
Liu, H., Yang, X., Liu, G., Liang, C., Xue, S., Chen, H., et al. (2017). Response of soil dissolved organic matter to microplastic addition in Chinese loess soil. Chemosphere 185, 907-917. doi: 10.1016/j.chemosphere.2017.07.064

Lozano, Y. M., and Rillig, M. C. (2020). Effects of microplastic fibers and drought on plant communities. Environ. Sci. Technol. 54, 6166-6173. doi: 10.1021/acs.est.0c01051

Machado, A. A. S., Lau, C. W., Kloas, W., Bergmann, J., Bachelier, J. B., Faltin, E., et al. (2019). Microplastics can change soil properties and affect plant performance. Environ. Sci. Technol. 53, 6044-6052. doi: 10.1021/acs. est.9b01339

Machado, A. A. S., Lau, C. W., Till, J., Kloas, W., Lehmann, A., Becker, R., et al. (2018). Impacts of microplastics on the soil biophysical environment. Environ. Sci. Technol. 52, 9656-9665. doi: 10.1021/acs.est.8b02212

Mahon, A. M., O’Connell, B., Healy, M. G., O'Connor, I., Officer, R., Nash, R., et al. (2017). Microplastics in sewage sludge: effects of treatment. Environ. Sci. Technol. 51, 810-818. doi: 10.1021/acs.est.6b04048

Materechera, S. A., Alston, A. M., Kirby, J. M., and Dexter, A. R. (1992). Influence of root diameter on the penetration of seminal roots into a compacted subsoil. Plant Soil 144, 297-303. doi: 10.1007/BF00012888

McCormack, M. L., Dickie, I. A., Eissenstat, D. M., Fahey, T. J., Fernandez, C. W., Guo, D., et al. (2015). Redefining fine roots improves understanding of below-ground contributions to terrestrial biosphere processes. New Phytol. 207, 505-518. doi: 10.1111/nph.13363

Nadian, H., Smith, S. E., Alston, A. M., and Murray, R. S. (1996). The effect of soil compaction on growth and $\mathrm{P}$ uptake by Trifolium subterraneum: interactions with mycorrhizal colonisation. Plant Soil 182, 39-49. doi: 10.1007/ BF00010993

Niu, W., Guo, Q., Zhou, X., and Helmers, M. J. (2012). Effect of aeration and soil water redistribution on the air permeability under subsurface drip irrigation. Soil Sci. Soc. Am. J. 76, 815-820. doi: 10.2136/sssaj2011.0329

Nizzetto, L., Futter, M., and Langaas, S. (2016). Are agricultural soils dumps for microplastics of urban origin? Environ. Sci. Technol. 50, 10777-10779. doi: 10.1021/acs.est.6b04140

Parniske, M. (2008). Arbuscular mycorrhiza: the mother of plant root endosymbioses. Nat. Rev. Microbiol. 6, 763-775. doi: 10.1038/nrmicro1987

Piehl, S., Leibner, A., Löder, M. G. J., Dris, R., Bogner, C., and Laforsch, C. (2018). Identification and quantification of macro- and microplastics on an agricultural farmland. Sci. Rep. 8:17950. doi: 10.1038/s41598-018-36172-y

Pietri, J. C. A., and Brookes, P. C. (2009). Substrate inputs and pH as factors controlling microbial biomass, activity and community structure in an arable soil. Soil Biol. Biochem. 41, 1396-1405. doi: 10.1016/j.soilbio.2009.03.017

Porter, W. M., Robson, A. D., and Abbott, L. K. (1987). Field survey of the distribution of vesicular-arbuscular mycorrhizal fungi in relation to soil $\mathrm{pH}$. J. Appl. Ecol. 24, 659-662. doi: 10.2307/2403900

Qi, Y., Ossowicki, A., Yang, X., Lwanga, E. H., Dini-Andreote, F., Geissen, V., et al. (2020). Effects of plastic mulch film residues on wheat rhizosphere and soil properties. J. Hazard. Mater. 387:121711. doi: 10.1016/j. jhazmat.2019.121711

Qi, Y., Yang, X., Pelaez, A. M., Lwanga, E. H., Beriot, N., Gertsen, H., et al. (2018). Macro- and micro- plastics in soil-plant system: effects of plastic mulch film residues on wheat (Triticum aestivum) growth. Sci. Total Environ. 645, 1048-1056. doi: 10.1016/j.scitotenv.2018.07.229

Ren, X., Tang, J., Liu, X., and Liu, Q. (2020). Effects of microplastics on greenhouse gas emissions and the microbial community in fertilized soil. Environ. Pollut. 256:113347. doi: 10.1016/j.envpol.2019.113347

Rillig, M. C. (2012). Microplastic in terrestrial ecosystems and the soil? Environ. Sci. Technol. 46, 6453-6454. doi: 10.1021/es302011r

Rillig, M. C. (2018). Microplastic disguising as soil carbon storage. Environ. Sci. Technol. 52, 6079-6080. doi: 10.1021/acs.est.8b02338

Rillig, M. C., Aguilar-Trigueros, C. A., Bergmann, J., Verbruggen, E., Veresoglou, S. D., and Lehmann, A. (2015). Plant root and mycorrhizal fungal traits for understanding soil aggregation. New Phytol. 205, 1385-1388. doi: 10.1111/nph.13045

Rillig, M. C., Aguilar-Trigueros, C. A., Camenzind, T., Cavagnaro, T. R., Degrune, F., Hohmann, P., et al. (2019a). Why farmers should manage the arbuscular mycorrhizal symbiosis. New Phytol. 222, 1171-1175. doi: 10.1111/ nph.15602

Rillig, M. C., and Lehmann, A. (2020). Microplastic in terrestrial ecosystems. Science 368, 1430-1431. doi: 10.1126/science.abb5979
Rillig, M. C., Lehmann, A., Machado, A. A. d. S., and Yang, G. (2019b). Microplastic effects on plants. New Phytol. 223, 1066-1070. doi: 10.1111/ nph.15794

Rillig, M. C., Lehmann, A., Ryo, M., and Bergmann, J. (2019c). Shaping up: toward considering the shape and form of pollutants. Environ. Sci. Technol. 53, 7925-7926. doi: 10.1021/acs.est.9b03520

Rillig, M. C., and Mummey, D. L. (2006). Mycorrhizas and soil structure. New Phytol. 171, 41-53. doi: 10.1111/j.1469-8137.2006.01750.x

Rillig, M. C., Ryo, M., Lehmann, A., Aguilar-Trigueros, C. A., Buchert, S., Wulf, A., et al. (2019d). The role of multiple global change factors in driving soil functions and microbial biodiversity. Science 366, 886-890. doi: 10.1126/science.aay 2832

Rillig, M. C., Sosa-Hernández, M. A., Roy, J., Aguilar-Trigueros, C. A., Vályi, K., and Lehmann, A. (2016). Towards an integrated mycorrhizal technology: harnessing mycorrhiza for sustainable intensification in agriculture. Front. Plant Sci. 7:1625. doi: 10.3389/fpls.2016.01625

Roberts, S. C., and Zembower, T. R. (2020). Global increases in antibiotic consumption: a concerning trend for WHO targets. Lancet Infect. Dis. 21, 10-11. doi: 10.1016/S1473-3099(20)30456-4

Romera-Castillo, C., Pinto, M., Langer, T. M., Álvarez-Salgado, X. A., and Herndl, G. J. (2018). Dissolved organic carbon leaching from plastics stimulates microbial activity in the ocean. Nat. Commun. 9:1430. doi: 10.1038/ s41467-018-03798-5

Sanders, I. R., Streitwolf-Engel, R., van der Heijden, M. G. A., Boller, T., and Wiemken, A. (1998). Increased allocation to external hyphae of arbuscular mycorrhizal fungi under $\mathrm{CO}_{2}$ enrichment. Oecologia 117, 496-503. doi: $10.1007 / \mathrm{s} 004420050685$

Scalenghe, R. (2018). Resource or waste? A perspective of plastics degradation in soil with a focus on end-of-life options. Heliyon 4:e00941. doi: 10.1016/j. heliyon.2018.e00941

Solaiman, Z. M., Abbott, L. K., and Varma, A. (2014). Mycorrhizal fungi: Use in sustainable agriculture and land restoration. Berlin: Springer.

Sosa-Hernández, M. A., Leifheit, E. F., Ingraffia, R., and Rillig, M. C. (2019). Subsoil arbuscular mycorrhizal fungi for sustainability and climate-smart agriculture: a solution right under our feet? Front. Microbiol. 10:744. doi: 10.3389/fmicb.2019.00744

Storer, K., Coggan, A., Ineson, P., and Hodge, A. (2018). Arbuscular mycorrhizal fungi reduce nitrous oxide emissions from $\mathrm{N}_{2} \mathrm{O}$ hotspots. New Phytol. 220, 1285-1295. doi: 10.1111/nph.14931

Thirkell, T. J., Charters, M. D., Elliott, A. J., Sait, S. M., and Field, K. J. (2017). Are mycorrhizal fungi our sustainable saviours? Considerations for achieving food security. J. Ecol. 105, 921-929. doi: 10.1111/1365-2745.12788

Thonar, C., Erb, A., and Jansa, J. (2012). Real-time PCR to quantify composition of arbuscular mycorrhizal fungal communitiesumarker design, verification, calibration and field validation. Mol. Ecol. Resour. 12, 219-232. doi: 10.1111/j. 1755-0998.2011.03086.x

Tilman, D., Cassman, K. G., Matson, P. A., Naylor, R., and Polasky, S. (2002). Agricultural sustainability and intensive production practices. Nature 418 671-677. doi: 10.1038/nature01014

van den Berg, P., Huerta-Lwanga, E., Corradini, F., and Geissen, V. (2020). Sewage sludge application as a vehicle for microplastics in eastern Spanish agricultural soils. Environ. Pollut. 261:114198. doi: 10.1016/j.envpol.2020.114198 van der Heijden, M. G. A., Bardgett, R. D., and van Straalen, N. M. (2008). The unseen majority: soil microbes as drivers of plant diversity and productivity in terrestrial ecosystems. Ecol. Lett. 11, 296-310. doi: 10.1111/j. 1461-0248.2007.01139.x

van der Heijden, M. G. A., Bruin, S. D., and Luckerhoff, L., van Logtestijn, R. S. P., and Schlaeppi, K. (2016). A widespread plant-fungal-bacterial symbiosis promotes plant biodiversity, plant nutrition and seedling recruitment. ISME J. 10, 389-399. doi: 10.1038/ismej.2015.120

Verbruggen, E., Jansa, J., Hammer, E. C., and Rillig, M. C. (2016). Do arbuscular mycorrhizal fungi stabilize litter-derived carbon in soil? J. Ecol. 104, 261-269. doi: $10.1111 / 1365-2745.12496$

Veresoglou, S. D., and Rillig, M. C. (2012). Suppression of fungal and nematode plant pathogens through arbuscular mycorrhizal fungi. Biol. Lett. 8, 214-217. doi: 10.1098/rsbl.2011.0874

Viollet, A., Pivato, B., Mougel, C., Cleyet-Marel, J. C., Gubry-Rangin, C., Lemanceau, P., et al. (2017). Pseudomonas fluorescens C7R12 type III secretion system impacts mycorrhization of medicago truncatula and associated microbial communities. Mycorrhiza 27, 23-33. doi: 10.1007/s00572-016-0730-3 
Wang, J., Liu, X., Li, Y., Powell, T., Wang, X., Wang, G., et al. (2019). Microplastics as contaminants in the soil environment: a mini-review. Sci. Total Environ. 691, 848-857. doi: 10.1016/j.scitotenv.2019.07.209

Wang, F., Zhang, X., Zhang, S., Zhang, S., and Sun, Y. (2020). Interactions of microplastics and cadmium on plant growth and arbuscular mycorrhizal fungal communities in an agricultural soil. Chemosphere 254:126791. doi: 10.1016/j.chemosphere.2020.126791

Weil, R. R., and Brady, N. C. (2017). The nature and properties of soils. 15th $E d n$. London: Pearson Education Limited.

Weithmann, N., Möller, J. N., Löder, M. G. J., Piehl, S., Laforsch, C., and Freitag, R. (2018). Organic fertilizer as a vehicle for the entry of microplastic into the environment. Sci. Adv. 4:eaap8060. doi: 10.1126/sciadvaap8060

Yu, H., Fan, P., Hou, J., Dang, Q., Cui, D., Xi, B., et al. (2020). Inhibitory effect of microplastics on soil extracellular enzymatic activities by changing soil properties and direct adsorption: an investigation at the aggregatefraction level. Environ. Pollut. 267:115544. doi: 10.1016/j.envpol.2020.115544
Zhang, M., Zhao, Y., Qin, X., Jia, W., Chai, L., Huang, M., et al. (2019). Microplastics from mulching film is a distinct habitat for bacteria in farmland soil. Sci. Total Environ. 688, 470-478. doi: 10.1016/j.scitotenv. 2019.06.108

Conflict of Interest: The authors declare that the research was conducted in the absence of any commercial or financial relationships that could be construed as a potential conflict of interest.

Copyright (c) 2021 Leifheit, Lehmann and Rillig. This is an open-access article distributed under the terms of the Creative Commons Attribution License (CC BY). The use, distribution or reproduction in other forums is permitted, provided the original author(s) and the copyright owner(s) are credited and that the original publication in this journal is cited, in accordance with accepted academic practice. No use, distribution or reproduction is permitted which does not comply with these terms. 